\title{
Towards a Cashless Society: The Effects of Perceived Convenience and Security on Gamified Mobile Payment Platform Adoption
}

\author{
P. C. Lai \\ University Malaya, Malaysia
}

\author{
Ewilly J.Y. Liew \\ Monash University Malaysia, Malaysia \\ ewilly.liew@monash.edu
}

\section{Abstract}

Integrating gamification into mobile payment platforms incentivizes people to use digital alternatives for payment and could spur user-centric, platform-mediated interactions. This study examines the relationship between perceived convenience and perceived security on individual users' intention to use a gamified mobile payment platform in Malaysia; a developing country envisioned to build a cashless society. The partial least square structural equation modeling (PLS-SEM) technique is employed on a final sample of 388 online users. The results show that perceived convenience has a strong but indirect effect on the intention to use. Perceived security has a strong and direct effect on intention to use and mediates the relationship between perceived convenience and intention to use. Furthermore, the reliability aspect of security is a top priority concern for users interested in using mobile payment. The multi-functional aspect of convenience is a top priority concern to attract users who are not interested in using mobile payment at first. The study discusses theoretical and practical implications for developing a dual strategy of 'ensuring convenience' and 'assuring security' to encourage the gamified mobile payment platform adoption in developing countries.

Keywords: mobile payment, gamification, perceived convenience, perceived security, developing country

\section{Introduction}

The emergence of digital platforms and new technologies has created a new trajectory for technology-mediated payment transactions and multichannel financial services delivery. Unlike the highly conservative and regulated banking industry, the non-banking service industry has been more fluid, flexible, and customizable (Alhassan, Li, Reddy, \& Duppati, 2020). Mobile payment in the service marketing industry provides consumers a cost-effective alternative to pay for products, services, and information transactions digitally via wireless technologies (Lai \& Scheela, 2018). Integrating gamification into the mobile payment platform as deliberate incorporation of user experience (UX) design element could spur a multichannel mobile marketing experience (Högberg, Shams, \& Wästlund, 2019; Lemon \& Verhoef, 2016).

Platform-mediated interactions between service providers and users play a central role in creating value (Mukerji \& Roy, 2019). Gamification on mobile payment platform capitalizes on user-centric interaction to encourage consumer engagement (Hofacker, de Ruyter, Lurie, Manchanda, \& Donaldson, 2016), motivate purchase decisions (Huotari \& Hamari, 2017), and ultimately, increase sales revenue (Ramadan \& Farah, 2017). Thus, there emerged a potential 
paradigm shift in the way businesses convert consumer engagement to actual sales anytime, anywhere.

The increasingly complex and diverse digital ecologies on the Internet have a significant impact on individuals and organizations living in a connected society (Linger \& Hasan, 2020). Within the platform ecosystem, businesses face pressures to diversify their marketing channels and make optimal pricing decisions (Zhang, Xu, \& Bai, 2020) for gaining competitive advantages and larger market shares. Mobile payment platforms open a new avenue for businesses to create an interactive marketing strategy that would reduce consumers' buying time and improve shopping quality.

Consumer-centric convenience is a significant contributing factor to advance the service economy (Cao \& Zhu, 2019) and accelerate mobile services such as in-app advertising (Truong, Nkhoma, \& Pansuwong, 2019), Internet banking (Kumar, Sachan, \& Kumar, 2020), and mobile payment (de Kerviler, Demoulin, \& Zidda, 2016; Teo, Tan, Ooi, Hew, \& Yew, 2015). Perceived convenience from a mobile payment perspective refers to consumers' perceived expenditures of time and effort to conduct payment transactions more readily (Berry, Seiders, \& Grewal, 2002; Gensler, Verhoef, \& Böhm, 2012). However, what businesses understood as consumercentric convenience, thereby influencing their marketing strategy decision, may not necessarily coincide with what consumers perceive as convenient.

Furthermore, a meta-analysis review conducted by Liu and colleagues (2019) found that consumers living in cash-centric developing countries are particularly positive towards adopting mobile payment. Plausible reasons could be the rapid proliferation of affordable smartphones and the rising awareness among tech-savvy consumers to catch up with fastpaced urban lifestyles (Poushter, Bishop, \& Chew, 2018). Due to these reasons, developing countries have a very high potential for using mobile payment platforms despite the relatively lower broadband Internet penetration (Lai \& Scheela, 2018; Mukerji \& Roy, 2019).

Nevertheless, not all developing countries have successfully implemented mobile payment solutions (Panhwer, Pitafi, Memon, \& Memon, 2020), subject to the country-level idiosyncratic risk and volatility. Also, unlike the developed counterparts, developing countries tend to have different development stages (Liew, Vaithilingam, \& Nair, 2014; Mukerji \& Roy, 2019; Sharma \& Gupta, 2009) that might affect consumer perception and intention to adopt mobile payment differently. Moreover, the regulatory environment is an essential aspect of mobile payment adoption that calls for attention, particularly among the developing countries. The UNESCO (Zelezny-Green, Voslon, \& Conole, 2018) reported that developing countries face four major barriers to increasing digital inclusion due to lack of infrastructure, affordability, user capabilities, and incentives (Schmida, Bernard, Zakaras, Lovegrove, \& Swingle, 2017). These barriers cause consumers to be sceptical about using "online money" and affect their interest in adopting mobile payment into their daily lifestyle. Perceived security refers to the degree to which consumers believe that using mobile payment procedures will be secure (Lai, 2017). Mobile payment consumers should feel certain and unthreatened that their personal and bank information provided for the transaction remains safe (de Kerviler et al., 2016; Kumar et al., 2020; Lai, 2017).

There has been a growing literature on mobile payment (Chen \& Li, 2017; de Kerviler et al., 2016; Miao \& Jayakar, 2016; O’Reilly, Duane, \& Andreev, 2012; Wu, Liu, \& Huang, 2017; Xin, Techatassanasoontorn, \& Tan, 2015). Meta-analysis results from sixty-one information systems (IS) studies highlighted the importance of usage intention and ascertained that perceived 
usefulness and perceived ease of use are among the top contributing factors to mobile payment system adoption (Liu et al., 2019). Most previous studies have employed dominant theoretical approaches to investigate mobile payment (Liu et al., 2019) such as the technology acceptance model (TAM) (Davis, 1989; Venkatesh \& Davis, 2000), the theory of planned behavior (TPB) (Taylor \& Todd, 1995), or unified theory of acceptance and use of technology (UTAUT) (Venkatesh, Morris, Gordon, \& Davis, 2003).

Apart from the above well-worn theoretical frameworks, there is an increasing need for incorporating consumer-centric measures (PWC, 2019) such as perceived value in terms of benefits and risks associated with mobile payment (de Kerviler et al., 2016). Perceptions of benefit and risk are inversely related and psychologically linked to consumers' overall affective evaluation of activity or technology (Alhakami \& Slovic, 1994). Value perceptions are crucial for success in the service industry (Boksberger \& Melsen, 2011). Nonetheless, systematic literature reviews have revealed a lack of focus on the effects of perceived convenience (benefit) and perceived security (cost of sacrifice) on user intention to adopt mobile payment (Liu et al., 2019; Ström, Vendel, \& Bredican, 2014). Little is also known about the relationship between perceived convenience and perceived security when incorporating gamification onto the mobile payment platform.

The motivation for conducting this study comes from our inquiry about the potential tradeoff between convenience and security concerns perceived by individual users interacting on the mobile platforms (Kim, Chan, \& Gupta, 2007). The potential trade-off could impede the effectiveness of gamified mobile payment platform adoption, resulting in detrimental effects to the overall success of e-commerce development in a country (Cao \& Zhu, 2019; Chaudhry, Farash, Naqvi, \& Sher, 2016). To address this gap in the literature, this study hopes to respond to Liu et al.'s (2019) call for considering 'the place where consumers live' as a potential factor that could affect consumer mobile payment adoption, thus contextualizing the current study to Malaysia.

Drawing from a value-based theoretical approach, this study seeks to examine the effects of perceived convenience and perceived security on consumers' intention to use a gamified mobile payment platform in Malaysia. Part of the novelty of this study is the use of blockchain technology and the incorporation of gamification as a user experience (UX) design element on a gamified mobile payment platform. We also explore multigroup differences based on user interest for mobile payment adoption (Chauhan, Mukhopadhyay, \& Jaiswal, 2018; Yuniarta \& Purnamawati, 2021). From an interactive marketing perspective, gamification on a mobile payment platform would encourage user engagement to act on incentives gained on mobile application (or app) towards making the actual purchase (Högberg et al., 2019) and meet the expectations of least digitally-skilled consumers (Colby \& Parasuraman, 2003). Consumers should feel comfortable and safe and be willing to use mobile payment to conduct transactions readily in their daily lives.

The rest of the paper is structured as follows. Section 2 outlines mobile payment development in Malaysia. Software architecture and design of a gamified mobile payment platform are outlined in the next section. Section 4 presents a review of relevant literature and hypotheses development. The methodology and empirical results are presented in Sections 5 and 6 . Theoretical and practical implications are discussed in the following Sections 7 and 8 . The paper concludes with summary remarks, limitations, and future research directions. 


\section{Mobile Payment Development in Malaysia}

In Malaysia, the government envisioned to build a cashless society by introducing the Interoperable Credit Transfer Framework (ICTF). Major mobile payment platform providers under the ICTF would eventually operate on a shared real-time Retail Payments Platform (RPP) (Lee \& Khaw, 2018). The central bank has issued forty-nine (49) licenses to platform providers generating a volume of 2.2 million mobile banking transactions, 7.59 million Internet banking transactions, and 1.92 million transactions to date (Bank Negara Malaysia, 2020). With about fifty mobile payment providers serving 32.4 million user populations in Malaysia, these providers compete for competitive intelligence to differentiate themselves in disrupting consumers' spending patterns and payment habits faster than their competitors (Chen, Zhu, $\&$ Xie, 2004).

Meanwhile, the global COVID-19 pandemic has stirred unprecedented safety concerns about coronavirus transmission via cash (Auer, Cornelli, \& Frost, 2020). World Health Organization (WHO) encourages contactless payment to prevent the spread of COVID-19 with physical cash notes handling (Huang, 2020). The Malaysian government has urged people to use cashless payment during COVID-19 by allocating MYR750 million (USD186 million) to drive mobile payment adoption (Fong, 2020) and introducing initiatives such as ePENJANA e-wallet stimulus, Shop Malaysia Online Initiative, and the Micro, Small and Medium Enterprises (MSME) e-commerce Campaign (The Star, 2020). The top five popular mobile payment apps that have recently gained traction in Malaysia are GrabPay, Touch n' Go eWallet, BoostPay, Fave, and BigPay based on a combined Apple and Android phone monthly active users' statistics (Chew, 2019). Increasing acceptance of these emerging platforms demonstrates a certain level of technology convergence in the national digital ecosystem that would afford successful implementation and commercialization of other similar platforms in Malaysia (Lai \& Scheela, 2018).

Mobile payment is gaining widespread acceptance in developing countries, accounting for $35 \%$ of global growth with a projected compound annual growth rate (CAGR) of $23.5 \%$ (Capgemini, 2019). More specifically, the Global Consumer Insight Survey (PWC, 2019) showed that amongst the top ten are developing countries in Southeast Asia, such as Thailand, Vietnam, Indonesia, Philippines, and Malaysia. Despite having the lowest mobile payment adoption rate amongst all, Malaysia has witnessed a promising year-over-year growth of $17 \%$ in 2019 (PWC, 2019). Indications of possible consumer-centric acceptance and resistance provide an avenue for this study to investigate factors that encourage or discourage users' intention to use mobile payment in Malaysia. This study would also provide insights for other countries that share a similar developmental trajectory of consumer perception and national digital infrastructure.

\section{Software architecture and design of a gamified mobile payment platform}

This study focuses on a gamified mobile payment platform that can integrate payment cards, the Internet, and mobile applications in one solution (Lai, 2017; Lai, Toh, \& Alkhrabsheh, 2019). The platform's software architecture was developed using blockchain technology akin to electronic coins in a smartphone-based shopping system deployed in Japan (Tashiro, 2018). Blockchain-based applications leverage the distributed peer-to-peer network such that each member in the blockchain network can openly access and directly verify peer-to-peer 
transactions without involving an intermediary or a central authority (Harrison, Hair, \& Ajjan, 2021). Each transaction is cryptographically secured and visibly stored on a blockchain as chronological, immutable, and auditable records to protect against fraud or malicious activities that compromise security aspects of the platform (Casino, Dasaklis, \& Patsakis, 2019).

Figure 1 depicts a general multi-tier software architecture of the gamified mobile payment platform. The primary layer is built on public blockchain technology using open-source cryptocurrencies such as Bitcoin and Ethereum. Smart contracts functionality of these cryptocurrencies will automatically execute peer-to-peer payment transactions that meet predetermined terms and conditions and electronically verify the chain of ownership using pairs of public keys (for identification) and private keys (authentication and encryption) (Nakamoto, 2008). The secondary layer comprises private blockchain technology for the database security protocol (Casino et al., 2019) and proprietary technology for scalability and payment tracing protocol (Lai, 2017). The third application layer contains business logic that determines how the platform will operate with the local context's rules and regulations. User identification will be verified in compliance with the National Bank of Malaysia's electronic Know-Your-Customer (e-KYC) guideline stipulated under the national anti-money laundering policy (Bank Negara Malaysia, 2019).

The presentation layer of a gamified mobile payment platform runs on the user's mobile device. Gamification enhances the mobile-based presentation layer with game-style rewards, which have found to positively attract user engagement (Högberg et al., 2019; Yang, Asaad, \& Dwivedi, 2017), trigger actual purchase decision (Huotari \& Hamari, 2017), and further increase the brand equity of participating stores (Xi \& Hamari, 2020). Gamification is a valueadding extension to any compatible software architecture of a mobile payment platform. The "Game on App" feature has a twofold function of engaging and motivating users for purchase (Alsawaier, 2018). In return, participating stores can analyze the shopping data of their customers who are also app users.

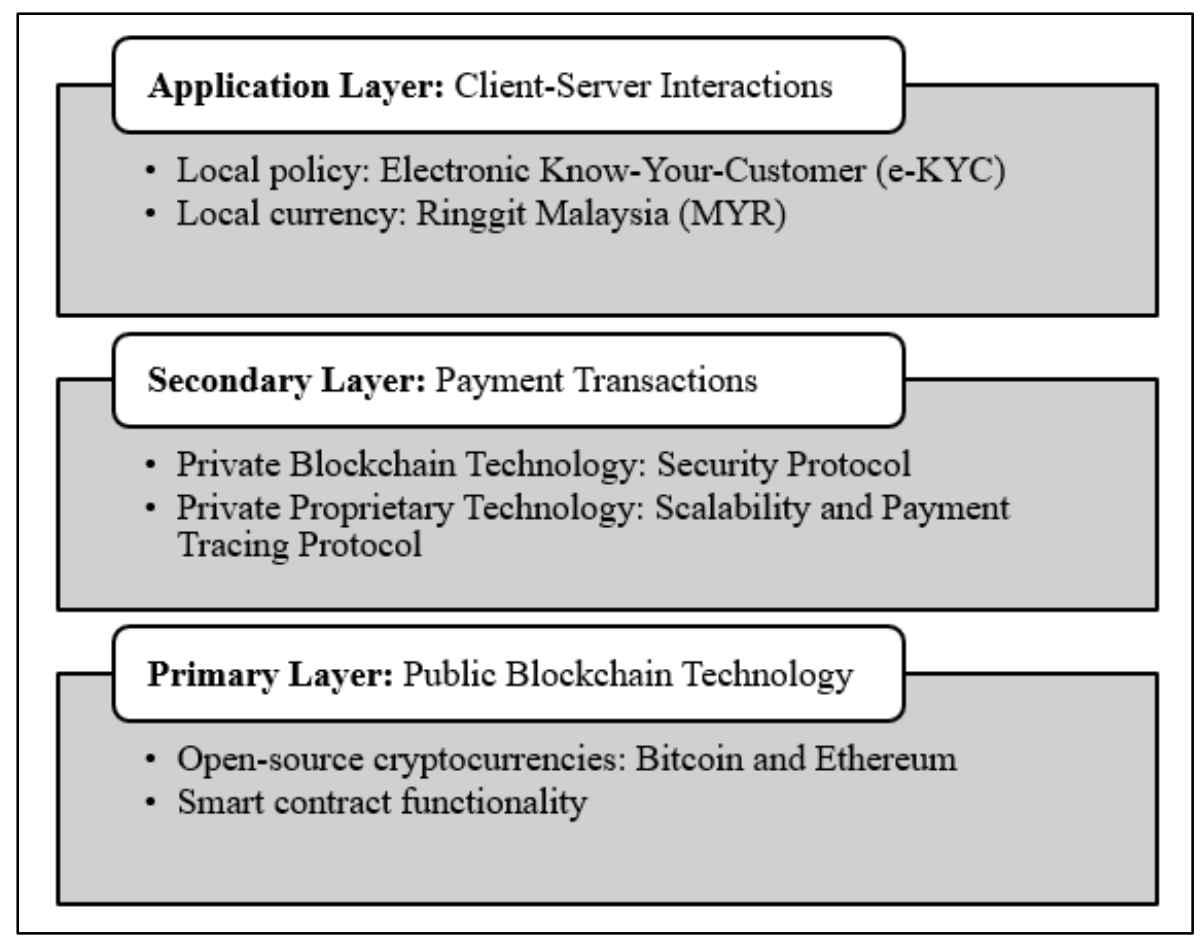

Figure 1. Software architecture of a gamified mobile payment platform 
Figures 2-4 illustrate the design mechanism of a gamified mobile payment platform. Loyalty point or stamp collection is typically used in incentive design for the retail or service industry (Huotari \& Hamari, 2017). Loyalty program that incorporates gamified elements could drive consumer motivation and engagement value (Hollebeek, Das, \& Shukla, 2021). The app allows users to convert the loyalty points earned into monetary tokens that can be used as digital money to pay for actual purchases transacted in any participating online or offline stores.

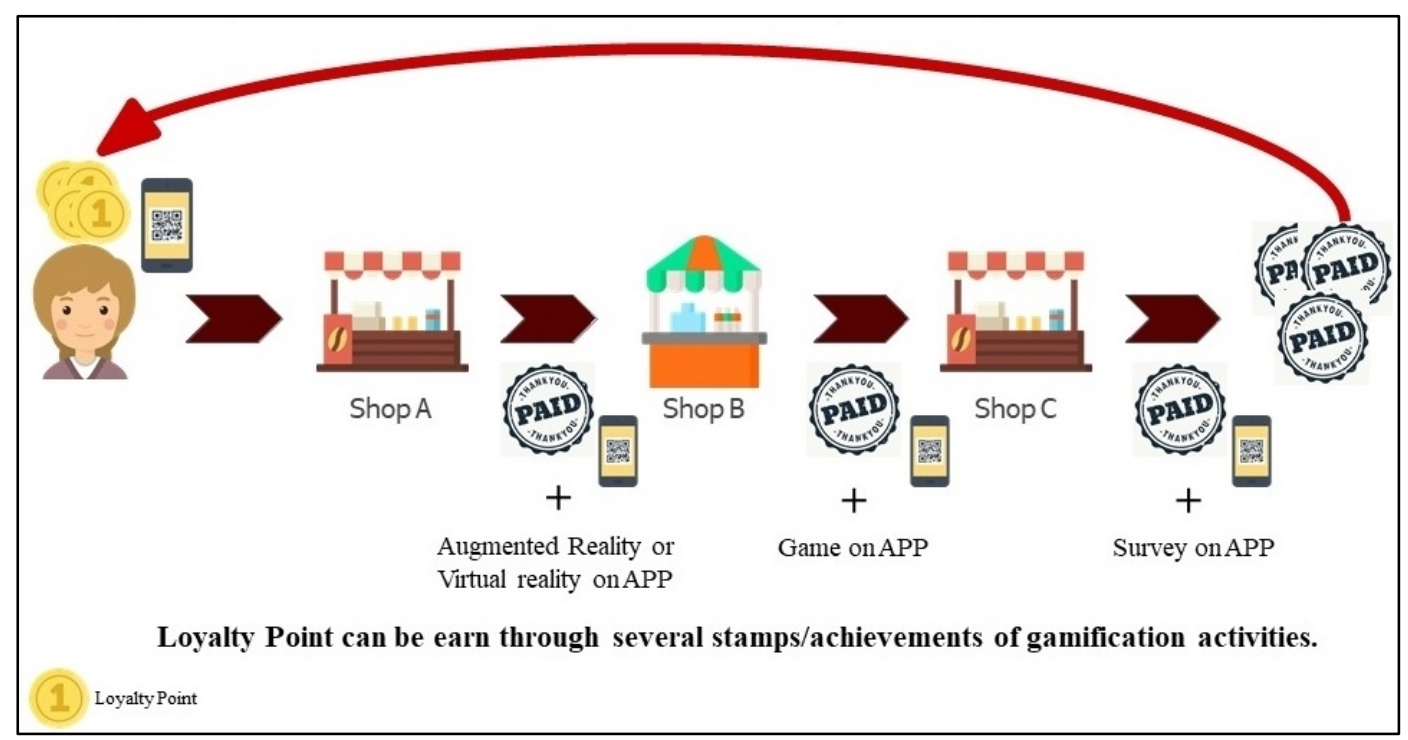

Figure 2. A user experience in earning loyalty points through Game on App (own illustration)

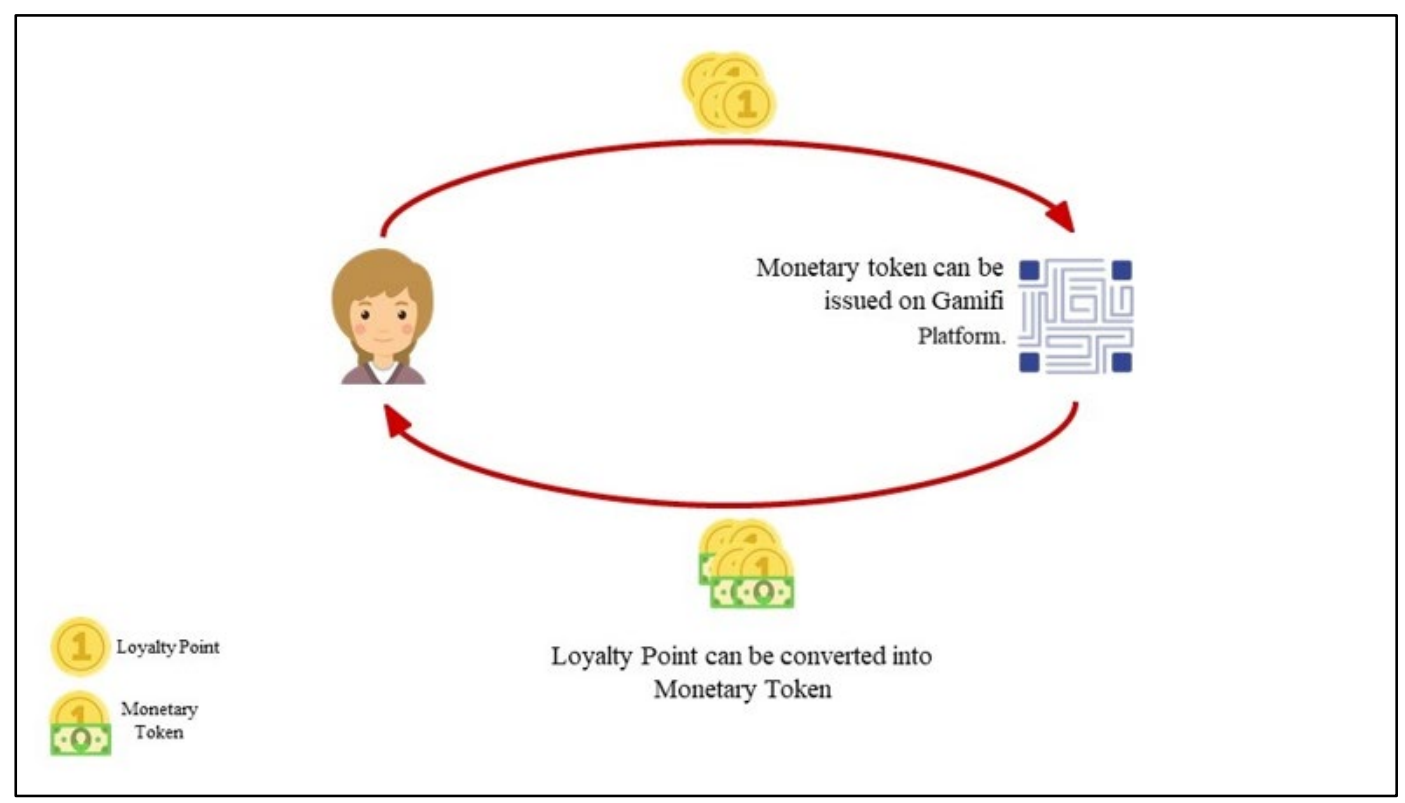

Figure 3. Converting loyalty points into blockchain monetary tokens (own illustration)

Figure 2 showed a user experience in collecting loyalty points or stamp through three different sets of gamification activities across three participating stores (shop A, shop B, and shop C). The user encounters an augmented reality or virtual reality experience on the app upon visiting the physical shop A. The user plays a game on the app designed for shop B and responds to a survey at shop C. The user earns loyalty points through a series of mobile games across the participating stores. Figure 3 shows that users can choose to convert the loyalty points earned into monetary tokens, i.e., electronic coins issued solely on the gamified mobile 
payment app. Following this, users can use the monetary tokens expressed in the local currency (i.e., Ringgit Malaysia) to pay for products, services, and information transacted at the participating stores (see Figure 4). Users can also share monetary tokens using peer-to-peer online money transfer for shopping purchases, commonly seen in developed countries but not as common in Malaysia.

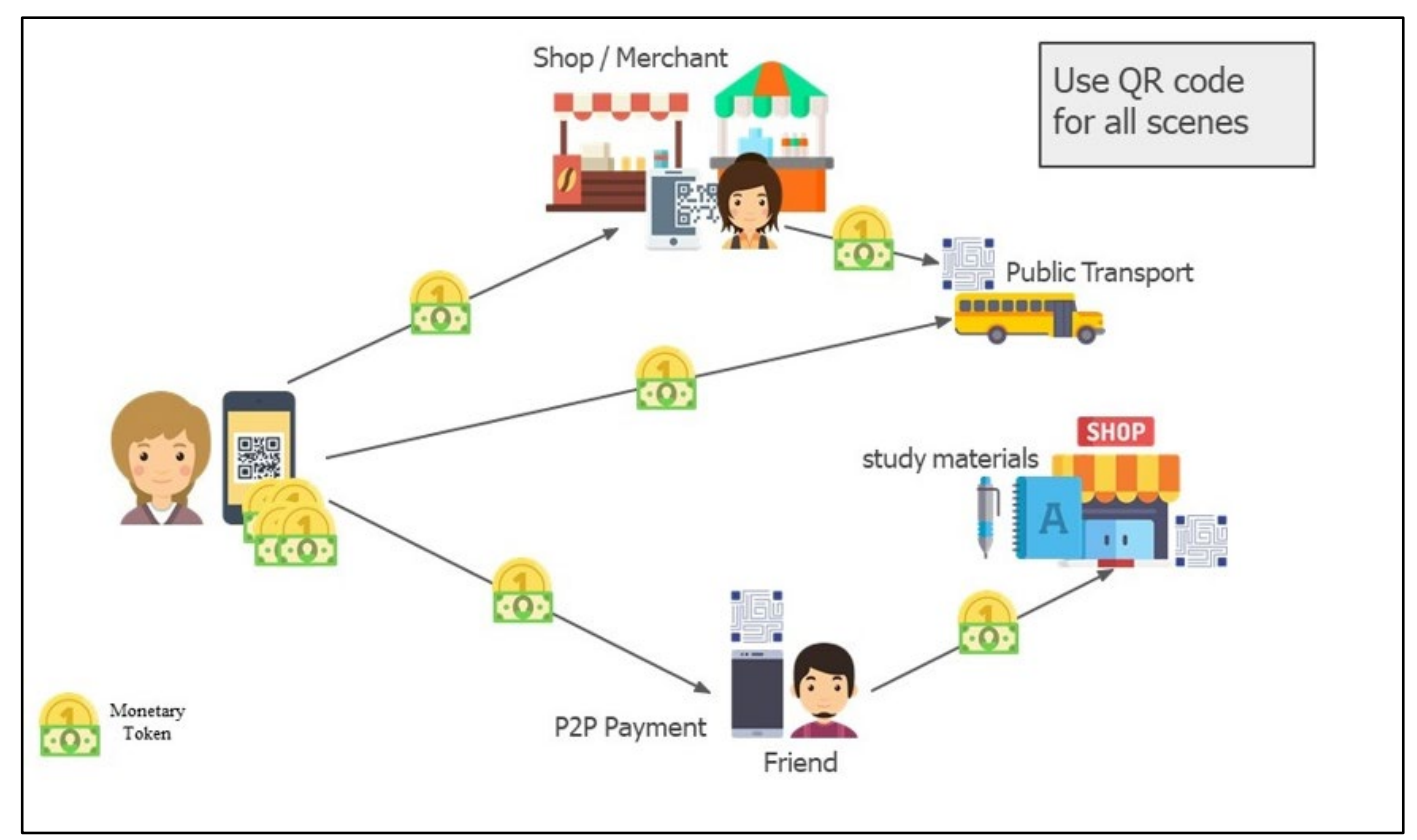

Figure 4. Using blockchain monetary tokens to pay for various transactions (own illustration)

The mobile payment platform ecosystem encompasses consumers' mobile devices, Internet data, payment details, and the retailers' point-of-sale (POS) system in a physical store or the checkout cart system on an online store (de Kerviler et al., 2016; Lai et al., 2019). Consumers have the site option to scan QR codes directly from the mobile payment app. They could also 'tap and pay' at the physical POS kiosk using mobile devices enabled with Near Field Communication (NFC) technology. The fastest straightforward approach would be performing payment transactions remotely from the store and directly on a multi-functional mobile payment platform (Lai \& Scheela, 2018).

\section{Literature Review and Hypotheses Development}

To date, Davis' (1989) Technology Acceptance Model (TAM) has transpired as one of the most employed models to study information technology adoption behavior, including mobile payment adoption and use at the individual level (Liu et al., 2019). Perceived usefulness (PU) and perceived ease of use (PEU) are two core constructs in TAM postulated for influencing users' attitudes and intentions towards various types of technology adoption (Davis, Bagozzi, \& Warshaw, 1989). There had been a high level of consensus among the mobile payment literature that PU and PEU have demonstrated significant positive impacts on consumers' intention to adopt and use mobile payment (Liu et al., 2019). Under such a circumstance, the inclusion of PU and PEU in the conceptual model might be overly generalized (Lim, 2018).

An alternative approach would be Kim, Chan, and Gupta's (2007) Value-based Adoption Model (VAM) from the value maximization perspective. The original VAM examines mobile Internet adoption among individuals who play a dual role of technology users and service 
consumers, similar to the context of mobile payment adoption (Kim et al., 2007). Due to the voluntary nature of adoption, users tend to evaluate the trade-off between total benefits received and total costs of sacrifice involved in using mobile payment services based on value perceptions (de Kerviler et al., 2016; Kim et al., 2007). From the utilitarian perspective of perceived value theory, individual will maximize positive utility (perceived benefits) and minimize negative utility (perceived costs of sacrifice) to assess the overall net utility of a product or service in the service industry (Boksberger \& Melsen, 2011; Sánchez-Fernández \& Iniesta-Bonillo, 2007). Convenience exemplifies perceived utilitarian value that appears particularly important for influencing mobile payment adoption (de Kerviler et al., 2016; Teo et al., 2015). In contrast, security risks represent perceived costs of sacrifice associated with consumption that negatively connote potential sacrifices in terms of monetary and psychological losses (de Kerviler et al., 2016).

Studies in Malaysia have extended TAM to include convenience and security as external stimuli in influencing PU and PEU for mobile payment adoption (Lai, 2017; Lai et al., 2019). However, Liu et al.'s (2019) meta-analysis of sixty-one (61) information systems (IS) studies found that neither perceived convenience nor perceived security correlates with PU and PEU for mobile payment adoption. This study decided not to include PU and PEU as the de facto variables in our conceptual model as we are more interested in examining the effects of convenience and security on adoption intention from the perceived value perspective (see Figure 5). VAM is preferred over TAM to appropriately evaluate the cost (i.e., perceived security) and benefit (i.e., perceived convenience) associated with adoption intention among consumers (Nayal, Pandey, \& Paul, 2021; Vishwakarma, Mukherjee, \& Datta, 2020).

Drawing from perceived value theory, this study proposed a research model that excludes TAM's core constructs, namely PU and PEU. Instead, our proposed model directly examines the effect of perceived convenience and perceived security on individual users' behavioral intention to use a gamified mobile payment platform in the service marketing industry. The proposed model also investigates the relationship between convenience and security; both were previously conceptualized as external constructs in TAM (Lai, 2017; Lai et al., 2019).

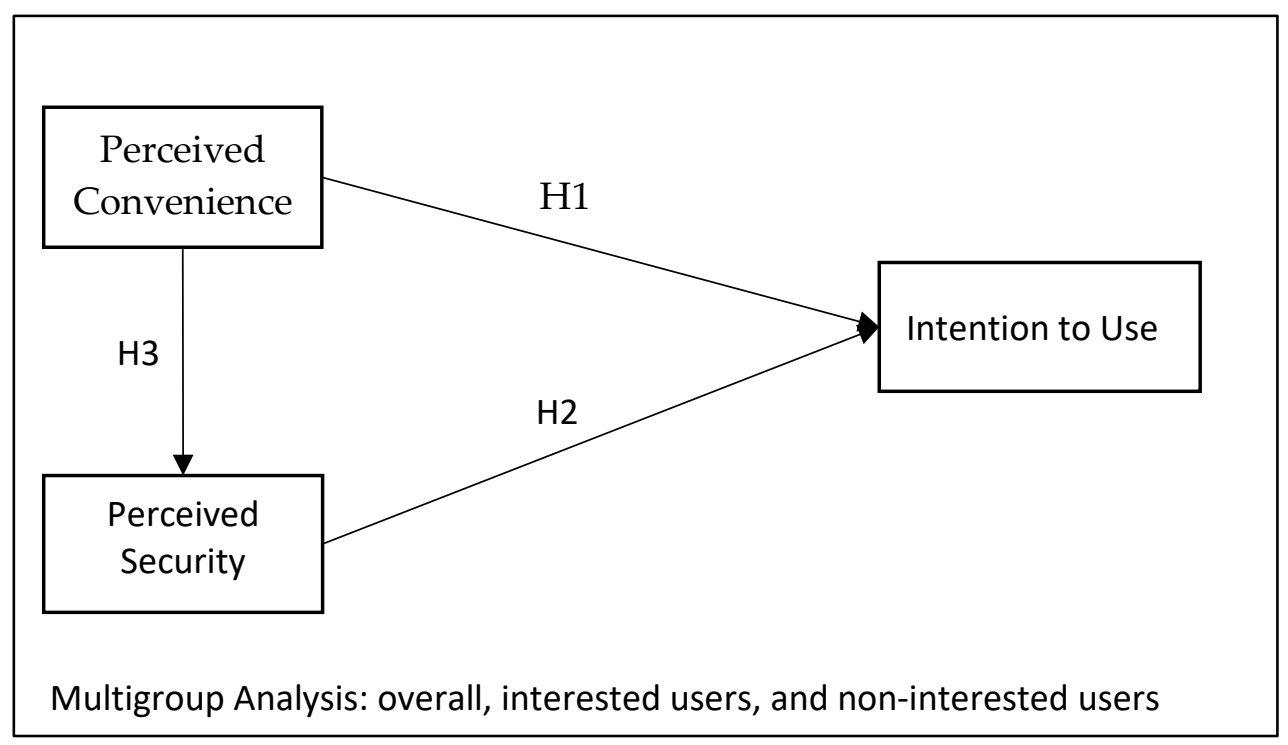

Figure 5. Proposed Research Model 


\subsection{Convenience}

The concept of perceived convenience has been popular in conventional shopping (Farquhar \& Rowley, 2009) and online shopping (Jiang, Yang, \& Jun, 2013) as essential for customer satisfaction and intention (Colwell, Aung, Kanetkar, \& Holden, 2008; Seiders, Voss, Godfrey, \& Grewal, 2007). Convenience is a crucial element of perceived value for e-commerce adoption (Weissman, 2012) and particularly mobile payment adoption (de Kerviler et al., 2016; Teo et al., 2015). Copeland (1923) first introduced the term convenience, referring to the degree to which little cognitive efforts are required for decision making, including time-buying or timesaving efforts. A product or service is deemed to be convenient if it saves time and reduces cognitive, emotional, and physical burdens for users (Chang \& Polonsky, 2012). In managing consumer behavior, Kaufmann (2014) argued that a consumer-centric definition of convenience is preferred over the researcher's definition. Furthermore, consumers' perceived convenience is a context-based concept that could vary from one context to another (Jiang et al., 2013), hence relevant to this study in examining the 'place' factor. The design of a gamified mobile payment platform should have consumers in mind - by understanding convenience from the consumers' perspective and where consumers live.

Past studies (de Kerviler et al., 2016; Kumar et al., 2020; Lai et al., 2019; Mukerji \& Roy, 2019) showed that consumers prefer convenient and practical mobile payment channels to pay for transactions anytime and anywhere on mobile phones. Time-poor consumers seek valueadding mobile payment services by evaluating benefits offered versus costs involved in making a mobile payment transaction (de Kerviler et al., 2016; Ström et al., 2014). This study conceptualizes perceived convenience as encompassing six aspects of utilitarian value: saving time, carrying less physical cash, an emergency need of funds, multi-functional design, customizes applications, and a single platform (Chang \& Polonsky, 2012; C. Kim, Mirusmonov, \& Lee, 2010; Lai et al., 2019).

Consistent with the concept of consumer-centric convenience, consumers will decide 'when' and 'where' to shop in their best interest. Mobile payment becomes appealing to consumers living in a cash-centric culture, typically among the developing countries (Liu et al., 2019). As users' desire for convenience mounts to the extent of frequently diverting to mobile payment as an alternative payment option, this study proposes that user intention to adopt mobile payment will increase. Gamification features on the mobile payment platform would incentify and attract the use of mobile payment. Thus, our first hypothesis is as follows:

H1: Perceived convenience positively impact intention to use gamified mobile payment.

\subsection{Security}

Security is an increasing concern in the platform ecosystem following the rapid growth of technology advancement and e-commerce offerings (Kumar et al., 2020; Lai, 2017; Liew et al., 2014; Morosan \& DeFranco, 2016). The cryptography of blockchain technology guarantees privacy and security protocol against malicious activities that alter the chain of peer-to-peer transactions (Casino et al., 2019). Unlike privacy that refers to user control over personal information, security connotes protection over the mobile payment platform from threats such as unauthorized intrusion, illegal theft, or destruction (Gupta \& Dubey, 2016; Lai, 2017; Liu et al., 2019; Shin, 2009). This study conceptualizes security as encompassing six aspects of the blockchain guarantees: reliability, privacy, authentication and authorization, integrity, nonrepudiation, and confidentiality (Casino et al., 2019; Lai, 2017). This study focuses on user 
perception of the level of security exposure distinctly different from the platform's inherent risks.

Past studies found that users' intention to use mobile payment is susceptible to the level of security exposure they perceive at the point of adoption (de Kerviler et al., 2016; Lai, 2017). Generally, users tend to accept a new payment alternative if they perceive lower security exposure (such as feeling reliable, safe, and unthreatened) that outweighs the old payment methods (Kumar et al., 2020; Lai, 2017). A reliable and trustworthy gamified mobile payment platform will incorporate sufficient security measures to assure users peace of mind in performing their transactions. Users hence do not need to worry about fraud, identity theft, or information leakage during the mobile payment process. This study proposes that favorable perceived security will assure users of the reliability, privacy, and safety concerns of using a gamified mobile payment platform. Thus, our second hypothesis is as follows:

H2: Perceived security positively impact intention to use gamified mobile payment.

\subsection{Convenience to Security}

The relationship between perceived convenience and perceived security for mobile payment adoption has been sidelined or subsumed under other variables of concern in past research (Liu et al., 2019). On the one hand, high profile service providers such as Apple, Google, Alibaba, Grab, AirAsia have sparked renewed interest around gamified mobile payment platforms that might trigger large-scale adoption towards a promising future of convenience (Johnson, Kiser, Washington, \& Torres, 2018). On the other hand, security and privacy have been significant barriers to adoption (Chutikulrungsee, 2016; Senarathna, Yeoh, Warren, \& Salzman, 2016), often subject to the country-level stages of development and digital infrastructure readiness, particularly in the developing context (Liew et al., 2014; Schmida et al., 2017).

The gamification on a mobile payment platform serves as a design of convenience that would encourage mobile payment use. In contrast, its monetary tokenization serves as a security measure to safeguard from unauthorized breaches. While studies seem to suggest that perceived convenience contributes to mobile payment adoption and perceived security requires further investigation (Lai et al., 2019; Weir, Douglas, Carruthers, \& Jack, 2009), Burmeister (2015) stressed the importance of security over convenience. Still, little is known whether perceived convenience and perceived security should co-exist for mobile payment adoption or would be a trade-off with an inverse relationship. The relationship might also vary across different groups of interested and non-interested users. This study proposes that perceived security would mediate the relationship between perceived convenience and intention to use a gamified mobile payment platform. The relationship between perceived convenience and perceived security might be akin to the effect from PEU to PU in the TAM. Users who perceive that little cognitive efforts are required to perform transactions using mobile payment (i.e., favorable perceived convenience) will form favorable perceived security that encourages intention to use a gamified mobile payment platform. Thus, our third hypothesis is as follows:

H3: Perceived convenience positively impacts perceived security. 


\section{Methodology}

\subsection{Data}

Data was collected using an online questionnaire survey based on a non-probabilistic purposeful sampling method. The study targeted only Malaysian users who have had experience purchasing goods or using services online over the past one (1) year using a gamified mobile payment platform. An email blast was sent to a list of 1358 users obtained from a series of ICT investor exhibition events held in the Klang Valley region of Malaysia. The questionnaire items for perceived convenience (6 items, C1-6), perceived security (6 items, S16), and intention to use (4 items, INT1-4) were adopted from past studies developed and validated in Malaysia (Lai, 2017; Lai et al., 2019).

\subsection{Sample Statistics}

The final sample contained 388 usable responses for further analysis after removing nonresponses and incomplete responses. Male users (230, 59.3\%) were more than female users $(158,40.7 \%)$, mostly in the age groups of $26-40(181,46.6 \%)$ and $41-55(102,26.3 \%)$. There were $87(22.4 \%)$ young users below 25 years old and 18 (4.6\%) elderly users above the retirement age of 56 . Most of the respondents were single $(204,52.6 \%)$ than married $(184,47.4 \%)$ and well educated with 264 of them $(68.0 \%)$ graduated from colleges or universities, 78 (20.1\%) from secondary or high school, and $46(11.9 \%)$ from graduate schools. Besides the 78 respondents still studying, most respondents were working in the ICT/ manufacturing sector $(172,44.3 \%)$, followed by other sectors $(67,17.3 \%)$, banking/ finance $(37,9.5 \%)$, and retail/ hypermarket (34, 8.8\%). 165 respondents were holding middle management positions (42.5\%), 56 junior management positions $(14.4 \%), 46$ professional positions $(11.9 \%), 24$ top management positions (6.2\%), and 97 other positions $(25.0 \%)$.

In particular, there were more interested users in using gamified mobile payment platform (240 (61.9\%) strongly interested; 14 (3.6\%) interested) compared to users who were just neutral $(106,27.3 \%)$ or not interested $(26,6.7 \%)$ or strongly not interested $(2,0.5 \%)$.

\subsection{Statistical Analysis}

A multivariate analysis based on the partial least squares structural equation modeling (PLSSEM) method was conducted using the SmartPLS 3 software (Ringle, Wende, \& Becker, 2015). The PLS-SEM emphasizes a causal-predictive approach to SEM that provides causal explanations without imposing distributional assumptions (Hair, Sarstedt, Ringle, \& Gudergan, 2018). In comparison, covariance-based CB-SEM has numerous restrictive assumptions and focuses on model fitting for theory confirmation (Hair, Risher, Sarstedt, \& Ringle, 2019). In this study, PLS-SEM was preferred as a non-parametric, variance-based approach to (i) explore a value-based theoretical framework that is lesser-known than the dominant TAM, (ii) explain the causal relationship between perceived convenience and perceived security on adoption intention, and (iii) predict individual users' intention to use a gamified mobile payment platform.

\section{Empirical Results}

This study followed Hair et al.'s (2019) research guidelines for evaluating the measurement and structural models in PLS-SEM. The measurement model satisfied all of the evaluation criteria for internal consistency reliability, convergent validity, and discriminant validity. The 
hypotheses of this study were tested in the structural model. Statistical inferences were based on the associated $t$-statistics above \pm 1.96 for a two-tailed test at the $5 \%$ level of significance.

\subsection{Measurement Model}

For construct reliability and validity, all constructs met the evaluation requirements with composite reliability $(\mathrm{CR})$ greater than the threshold of 0.70 and average variance extracted (AVE) greater than the threshold of 0.50 (see Table 1). Almost all of the item loadings were greater than 0.708 , with most of the items above 0.800 . Only one item (S4) had a loading of 0.646 but did not significantly threaten the internal consistency and convergent validity of the related construct (i.e., security) (Hair et al., 2018); $C R=0.917$, AVE=0.691 (excluded) versus $\mathrm{CR}=0.914, \mathrm{AVE}=0.643$ (included). Hence item $\mathrm{S} 4$ was retained in the model. The latent variable correlation between constructs was also reported in Table 1 .

\begin{tabular}{|l|l|l|l|l|l|}
\hline & CR & AVE & Convenience & Security & Intention to use \\
\hline Convenience & 0.961 & 0.806 & 1.000 & & \\
\hline Security & 0.914 & 0.643 & 0.516 & 1.000 & \\
\hline Intention to Use & 0.909 & 0.714 & 0.426 & 0.573 & 1.000 \\
\hline
\end{tabular}

Table 1. Construct Reliability, Validity, and Latent Variable Correlation

Discriminant validity of the constructs was established based on Henseler, Ringle, and Sarstedt's (2015a) heterotrait-monotrait ratio of correlations (HTMT). Table 2 showed that all inter-construct HTMT values were below the HTMT.85 criterion threshold of 0.85 , and the twotailed $95 \%$ bias-corrected confidence intervals of HTMT were within the unit interval. The model fit was achieved based on the standardized root means square residual (SRMR) of 0.088 below the threshold of 0.10 (Henseler et al., 2014). Table 3 showed that the measurement model did not have a multicollinearity issue, as all inner VIF values were below the threshold of 3.3 (Hair, Hult, Ringle, \& Sarstedt, 2014).

\begin{tabular}{|l|l|l|l|}
\hline & Convenience & Security & Intention to Use \\
\hline Convenience & & & \\
\hline Security & $0.545^{* * *}$ & & \\
& {$[0.387,0.666]$} & & \\
\hline Intention to Use & $0.463^{* * *}$ & $0.649^{* * *}$ & \\
& {$[0.318,0.578]$} & {$[0.491,0.757]$} & \\
\hline
\end{tabular}

Table 2. Discriminant Validity Assessment based on HTMT Criterion

Note: Significance level (bootstrapped) ${ }^{* * *} \mathrm{p}<0.01,{ }^{* *} \mathrm{p}<0.05,{ }^{*} \mathrm{p}<0.10$, n.s. non-significant. The values in brackets represent the $95 \%$ bias-corrected confidence interval of the HTMT values obtained from a bootstrapping procedure with 5000 resamples.

\begin{tabular}{|l|l|l|}
\hline & Convenience & Security \\
\hline Convenience & & \\
\hline Security & 1.000 & \\
\hline Intention to Use & 1.362 & 1.362 \\
\hline
\end{tabular}

Table 3. Inner VIF values

\subsection{Structural Model}

For hypotheses testing, the structural model was run with a bootstrapping procedure of 5000 resamples based on a distribution-free sampling method. Based on $\mathrm{R}^{2}$ statistics, the model explained a $35.2 \%$ variance of users' intention to use a gamified mobile payment platform. In 
particular, perceived convenience explained a $26.6 \%$ variance of perceived security. All three hypotheses were supported.

From Table 4 , the results showed that perceived convenience had a strong direct positive effect on perceived security $(\beta=0.516, p<0.000)$, but a weak direct positive effect on users' intention to use $(\beta=0.178, p<0.002)$. The latter effect was weaker than the former, based on the magnitude of the path coefficients. Perceived convenience had a moderate indirect effect $(\beta=0.248$, $p<0.000)$ but a strong total effect $(\beta=0.426, p<0.000)$ on users' intention to use. Compared to the total effect of perceived convenience, perceived security still had a stronger direct positive effect on the intention to use $(\beta=0.482, p<0.000)$. The total effect of perceived security is the same as its direct effect. Based on Cohen's (1988) $f^{2}$ statistics, perceived convenience had a large effect size on security $\left(f^{2}=0.362\right)$ but very small effect size on the intention to use $\left(f^{2}=\right.$ $0.036)$, whereas perceived security had a medium effect size on the intention to use $\left(f^{2}=0.263\right)$.

\begin{tabular}{|l|l|l|l|l|l|}
\hline \multicolumn{2}{|l|}{ Hypothesized relationships } & Direct Effect & Effect size $f^{2}$ & Indirect Effect & Total Effect \\
\hline H1 & Convenience $\rightarrow$ Intention to Use & $\begin{array}{l}0.178 \\
(3.168)^{* * *}\end{array}$ & $0.036(1.315)^{\text {n.s. }}$ & $\begin{array}{l}0.248 \\
(6.285)^{* * *}\end{array}$ & $\begin{array}{l}0.426 \\
(7.436)^{* * *}\end{array}$ \\
\hline H2 & Security $\rightarrow$ Intention to Use & 0.482 & $0.263(2.855)^{* * *}$ & - & 0.482 \\
& & $(7.987)^{* * *}$ & & & $(8.021)^{* * *}$ \\
\hline H3 & Convenience $\rightarrow$ Security & 0.516 & $0.362(2.819)^{* * *}$ & - & 0.516 \\
& & $(9.108)^{* * *}$ & & & $(9.148)^{* * *}$ \\
\hline
\end{tabular}

Table 4. Direct, Indirect, Total Effects of Hypothesized Relationships

Note: Significance level (bootstrapped) ${ }^{* * *} \mathrm{p}<0.01,{ }^{* *} \mathrm{p}<0.05,{ }^{*} \mathrm{p}<0.10$, n.s. non-significant.

Cohen's f^2 effect size threshold: Large $>0.35$, medium $>0.15$, small $>0.02$.

The blindfolding procedure showed that all construct cross-validated redundancy $\mathrm{Q}^{2}$ values were above the threshold of zero; $Q^{2}=0.152$ for security and $Q^{2}=0.230$ for intention to use. Hence sufficient predictive relevance of the structural model was established.

\begin{tabular}{|l|c|c|c|c|c|c|c|c|c|c|c|}
\hline \multirow{2}{*}{$\begin{array}{l}\text { Predicted } \\
\text { Indicators }\end{array}$} & \multicolumn{3}{|c}{ PLS-SEM prediction } & \multicolumn{3}{c|}{ Linear Model (LM) prediction } & \multicolumn{3}{c|}{ PLS-SEM versus LM } \\
\cline { 2 - 13 } & RMSE & MAE & MAPE & $\mathrm{Q}^{2}$ & RMSE & MAE & MAPE & Q $^{2}$ & RMSE & MAE & MAPE \\
\hline INT1 & 0.491 & 0.403 & 18.895 & 0.196 & 0.484 & 0.381 & 17.877 & 0.221 & LM & LM & LM \\
\hline INT2 & 0.562 & 0.489 & 22.839 & 0.098 & 0.566 & 0.492 & 22.930 & 0.084 & PLS & PLS & PLS \\
\hline INT3 & 0.565 & 0.478 & 22.690 & 0.036 & 0.565 & 0.488 & 23.130 & 0.036 & LM & PLS & PLS \\
\hline INT4 & 0.502 & 0.397 & 18.491 & 0.132 & 0.518 & 0.408 & 18.831 & 0.077 & PLS & PLS & PLS \\
\hline S1 & 0.491 & 0.326 & 17.308 & 0.219 & 0.497 & 0.310 & 16.533 & 0.198 & PLS & LM & LM \\
\hline S2 & 0.568 & 0.475 & 23.613 & 0.236 & 0.580 & 0.464 & 23.026 & 0.203 & PLS & LM & LM \\
\hline S3 & 0.638 & 0.433 & 16.842 & 0.066 & 0.646 & 0.437 & 17.219 & 0.041 & PLS & PLS & PLS \\
\hline S4 & 0.687 & 0.558 & 19.988 & 0.034 & 0.681 & 0.544 & 19.824 & 0.051 & LM & LM & LM \\
\hline S5 & 0.561 & 0.482 & 22.888 & 0.179 & 0.565 & 0.481 & 22.913 & 0.166 & PLS & LM & PLS \\
\hline S6 & 0.508 & 0.428 & 19.419 & 0.177 & 0.514 & 0.428 & 19.478 & 0.156 & PLS & PLS & PLS \\
\hline
\end{tabular}

Table 5. Comparing Information Criteria between PLS-SEM and LM Predictions

Note: The intention to use indicators (INT1-4) were predicted using convenience indicators (C1-6) on hypothesis $\mathrm{H} 1$ and security indicators (S1-6) on hypothesis $\mathrm{H} 2$. The security indicators (S1-6) were predicted using convenience indicators (C1-6) on hypothesis H3. Comparisons were made based on which model has the lower value of information criteria - root mean squared error of predictions (RMSE), mean absolute error (MAE), mean absolute percentage error (MAPE), and blindfolding-based $\mathrm{Q}^{2}$.

Using a PLSPredict procedure, this study assesses the predictive relevance of the empirical findings. The PLS Predict procedure was conducted on 10-fold cross-validation using training estimates from the PLS-SEM model to predict the testing sample (Shmueli et al., 2019). Table 
5 shows that all indicators predicted in the PLS-SEM model had $\mathrm{Q}^{2}$ values greater than the zero thresholds. Moreover, the PLS-SEM model outperformed the linear regression model (LM) with lower values of prediction errors (RMSE, MAE, and MAPE) for the majority of predicted indicators (i.e., 18 out of 30). The results indicated that the PLS-SEM model has medium predictive power and is better than a linear model prediction.

Observed heterogeneity might likely present in this study, depending on the types of users. Users with different levels of prior interest in using a gamified mobile payment platform may perceive convenience and security differently (Chauhan et al., 2018; Yuniarta \& Purnamawati, 2021). First, the study needs to ascertain if a meaningful multigroup comparison exists across interested users, non-interested users, and all users.

A measurement invariance of the composite models (MICOM) procedure was conducted to assess the measurement invariance of the empirical model (Henseler, Ringle, \& Sarstedt, 2015b; Henseler et al., 2015). Based on the results, the empirical model established configural invariance (identical PLS models, data treatment, and algorithm settings) but not the composite invariance. The results of 1000 permutations in Table 6 shows that convenience is the only construct with between-group correlation c (0.999) not significantly different from 1 $(\mathrm{p}=0.121>0.05)$. As such, a multigroup comparison using the empirical model would not be meaningful. However, this study could still provide a separate analysis of each user group without comparing the results between interested users and non-interested users.

\begin{tabular}{|c|c|c|c|c|}
\hline Constructs & Correlation, c & $\begin{array}{c}95 \% \text { confidence } \\
\text { interval }\end{array}$ & p-value & $\begin{array}{c}\text { Compositional } \\
\text { invariance? }\end{array}$ \\
\hline Convenience & 0.999 & {$[0.999,1.000]$} & 0.121 & Yes \\
\hline Intention to Use & 0.923 & {$[0.991,0.997]$} & 0.000 & No \\
\hline Security & 0.987 & {$[0.994,0.998]$} & 0.006 & No \\
\hline
\end{tabular}

Table 6. Measurement Invariance Assessment

Finally, Ringle and Sarstedt's (2016) importance-performance map analysis (IPMA) was conducted to gain additional insights into the effects of perceived convenience and perceived security on users' intention to use a gamified mobile payment platform. IPMA contrasted the importance of hypothesized relationships (based on unstandardized total effects of the PLS estimates) with the performance of related constructs (based on average latent variable scores rescaled on 0-100). IPMA aims to identify priority areas of constructs and indicators that exhibit high-importance but low-performance scores to guide managerial prioritization for performance improvement (Ringle \& Sarstedt, 2016).

Based on the IPMA results at the construct level, Table 7 shows that security could be a priority area for performance improvement among interested users and all users. In contrast, noninterested users would prioritize convenience for performance improvement. The constructlevel results found that the security construct shows higher importance ( 0.46 for all users, 0.483 for interested users) but also higher performance (40.59 for all users, 37.31 for interested users). Prioritizing security is still possible (Ringle \& Sarstedt, 2016) and preferred as the PLS-SEM results have previously shown that security is strongly contributing to the total effect of convenience. Thus, improving perceived security will indirectly improve perceived convenience, even though the latter has lower performance scores than the former. However, for non-interested users, the convenience construct is clearly a priority area with higher importance (0.258) but lower performance (37.44) scores. 


\begin{tabular}{|l|c|c|c|c|c|c|}
\hline & \multicolumn{3}{|c|}{ Importance } & \multicolumn{3}{c|}{ Performance } \\
Construct level: & $\begin{array}{c}\text { All } \\
(\mathrm{n}=388)\end{array}$ & $\begin{array}{c}\text { Interested } \\
(\mathrm{n}=254)\end{array}$ & $\begin{array}{c}\text { Non- } \\
\text { interested } \\
(\mathrm{n}=132)\end{array}$ & $\begin{array}{c}\text { All } \\
(\mathrm{n}=388)\end{array}$ & $\begin{array}{c}\text { Interested } \\
(\mathrm{n}=254)\end{array}$ & $\begin{array}{c}\text { Non- } \\
\text { interested } \\
(\mathrm{n}=132)\end{array}$ \\
\hline Convenience & 0.444 & 0.451 & 0.258 & 31.88 & 28.62 & 37.44 \\
\hline Security & 0.460 & 0.483 & 0.111 & 40.59 & 37.31 & 47.34 \\
\hline
\end{tabular}

Table 7. IPMA Construct-level Priority Areas for Performance Improvement

Note: Importance based on total effects (x-axis), performance scores on the intention to use (y-axis).

On average, a 1-unit increase in security would increase users' intention to use (performance) by $0.46 \%$ for all users and $0.483 \%$ for interested users (importance). Security improvement would affect interested users slightly more than all users. In contrast, among the noninterested users, a 1-unit increase in convenience would increase users' intention to use (performance) by $0.258 \%$. The results show that the impact of improving security concerns for interested users is larger than improving convenience concerns for non-interested users.

Based on the IPMA results at the indicator level, Table 8 shows the top 5 priority sub-areas for performance improvement that have indicators with high importance (total effects $\geq 0.08$ ) but below-average performance (intention to use $\leq 0.50$ ).

Among all users and the interested users, the top 5 priority sub-areas were mostly concerning security issues though in different order of importance. Four of these indicators reflect the security aspects of reliability (S1), privacy (S2), non-repudiation (S5), and confidentiality (S6), except for one indicator representing the convenience of carrying less cash (C1). Reliability (S1) topped the list with the highest importance (0.093) but the lowest performance score (28.54) for all users. Although reliability (S1) was ranked third in terms of importance (0.093), it too had the lowest performance score (23.819) for the interested users. Hence, the indicatorlevel results showed that the reliability (S1) aspect of a gamified mobile payment platform should have the top priority for performance improvement among interested users and all users.

\begin{tabular}{|c|c|c|c|c|c|c|c|c|}
\hline \multicolumn{3}{|c|}{ All $(\mathrm{n}=\mathbf{3 8 8})$} & \multicolumn{3}{c|}{ Interested $(\mathrm{n}=254)$} & \multicolumn{3}{c|}{ Non-interested $(\mathrm{n}=132)$} \\
\hline Ind. & IMP & PERF & Ind. & IMP & PERF & Ind. & IMP & PERF \\
\hline S1 & $\mathbf{0 . 0 9 3}$ & $\mathbf{2 8 . 5 4}$ & S6 & 0.098 & 39.08 & C2 & $\mathbf{0 . 0 5 3}$ & $\mathbf{3 2 . 7 7}$ \\
\hline S6 & 0.092 & 42.59 & C1 & 0.096 & 33.20 & C3 & 0.045 & 36.74 \\
\hline S2 & 0.085 & 35.05 & S1 & $\mathbf{0 . 0 9 3}$ & $\mathbf{2 3 . 8 2}$ & C5 & 0.043 & 37.31 \\
\hline C1 & 0.084 & 37.08 & S2 & 0.084 & 29.53 & C4 & 0.042 & 38.07 \\
\hline S5 & 0.083 & 39.63 & S5 & 0.083 & 34.84 & C6 & 0.039 & 38.26 \\
\hline
\end{tabular}

Table 8. IMPA Indicator-level Priority Areas for Performance Improvement

Note: Ind = indicator. Importance is based on unstandardized total effects (IMP); Performance is based on rescaled average latent variable scores (PERF)

On the other hand, non-interested users were mostly concerned with the convenience of having multi-function (C2), an emergency need of funds (C3), time-saving (C4), customized application (C5), and a single platform (C6); security was not listed among the top priorities. Multi-function (C2) had the highest importance (0.053) but the lowest performance score (32.77). Hence, the multi-functional aspect of a gamified mobile payment platform should have the top priority for performance improvement among the non-interested users. 


\section{Theoretical Contributions}

The empirical results supported the hypotheses in this study that users' value perceptions of convenience and security positively impact their intention to use a gamified mobile payment platform. Perceived security has a strong and direct influence on intention to use, while perceived convenience has a strong but indirect influence on intention to use via perceived security. The direct effect size from perceived convenience to intention to use was not significant. The results shed light on the relationship between convenience and security and how the strong bond of this relationship positively impacts mobile payment adoption. Hence, platform providers and policymakers should focus on the dual strategy of 'ensuring convenience' and 'assuring security' to encourage the use of a gamified mobile payment platform. The results have implications for developing countries that share a similar development trajectory like Malaysia.

The sample demographic profile showed that more users were interested $(n=254)$ and in favor of using a gamified mobile payment platform than users who are neutral or not interested $(n=132)$. When users' interests were analyzed separately because a multigroup analysis was not feasible, this study found two different results. For all users, particularly the interested users, the 'reliability' aspect of security should be prioritized for enhancing their intention to use a gamified mobile payment platform. However, for the non-interested users, the 'multifunctional' aspect of convenience should be prioritized for encouraging their adoption intention. The results provide insights on developing strategies that could ensure the multifunctional design of convenience to attract non-interested users and assure the reliability aspect of security to retain interested users.

\section{Practical Implications}

Malaysia has witnessed increasing digital readiness among individual and business users due to various technological reforms and initiatives led by the government. In collaboration with private telecommunication companies, the Malaysian government has rigorously encouraged high-speed broadband and 4G mobile Internet in urban and rural areas (Economic Planning Unit, 2015). The success of mobile payment implementation in a volatile and competitive platform market calls for both demand-side and supply-side preconditions to work in harmony. For individual users, their intention to use a gamified mobile payment platform is dependent on the synergy between marketers' design strategies and the country's digital infrastructure. Among the business users, informal institutions of co-investing and networking (e.g., business angel ecosystem) are supporting investors and small-medium enterprises (SMEs) to contend with political, legal, and financial challenges in Malaysia (Harrison, Scheela, Lai, \& Vivekarajah, 2018).

Our gamified mobile payment platform has proven to be a step forward towards providing empirical support to the conceptualization of blockchain-based cryptocurrency and mobile payment. $\mathrm{Xu}$ and colleagues (2020) considered this combination as attractive in developing countries that have barriers to digital adoption in general. Additionally, incorporating gamification as a design element in our platform has positively fostered user engagement for using cryptocurrency mobile payment services in Malaysia. Our study provides empirical evidence that encourage the usage of a gamified mobile payment platform in a developing country (Putri et al., 2019) and mitigate some human-related concerns in the emerging decentralized blockchain ecosystem (Parizi \& Dehghantanha, 2018). 
In ensuring the multi-functional aspect of convenience, various gamification activities or reward programs by the participating stores can be designed into the app architecture for user perusal. Users could earn loyalty points from a series of e-stamp collection, converting the points earned into monetary tokens of real currency to pay for transactions in a single gamified mobile payment platform. Furthermore, users could also top up monetary tokens through online banking, Internet payment (e.g., debit card, credit card, PayPal), and mobile payment. In Malaysia, Boost introduced a rewarding cashless experience through various features like BoostUP 'shake' rewards, CashUP cashback savings, QR payment services for users to earn ecoins or 'shake' for cashbacks and rewards (Boost, 2019). The rapid advancement of affordable smartphones and 5G technology could accelerate the multi-functional, multichannel financial services delivery (Kumar et al., 2020) in a single platform.

In assuring the reliability aspect of security, features like the pin, picture, One-Time Password (OTP), finger, or facial recognition can be designed onto the app architecture for user authentication. Within the mobile payment platform ecosystem, various security standards and protocols are available to reduce the associated risks with blockchain technology and mobile payment (Casino et al., 2019; Lai, 2017). They safeguard authentication, encryption, integrity, and non-reputability within the blockchain ecosystem (Casino et al., 2019) and have become more common across the mobile platform industry. In Malaysia, local regulations such as the ISO 27000 series of standards are formulated to assure information security. To unlock the full features of any mobile wallet platform, Malaysian users must verify their identity via electronic Know-Your-Customer (eKYC) verification using a registered Malaysia mobile number, a selfie photo, and a matching national identity card or passport (Bank Negara Malaysia, 2019). Platform service providers or marketers should incorporate security compliance into the software architecture and design of a gamified mobile payment platform to meet the standard national security and data protection regulation even in the non-banking service industry.

Understanding users' value perceptions over the platform's design and security concerns is a step towards mitigating a common misperception that users would naturally switch to any new mobile payment option in the market (Lai \& Scheela, 2018). Moreover, businesses need to strategize engagement towards targeting the right type of users by understanding user interests under their perception of adopting and using a gamified mobile payment platform.

\section{Conclusion, limitations, and future directions}

This study contributes to the literature by explicitly examining the relationship between perceived convenience and perceived security on users' intention to use a gamified mobile payment platform. Perceived convenience had a strong but indirect positive effect on intention to use, while perceived security had a strong and direct positive effect on intention to use. Perceived security mediates the relationship between perceived convenience and intention to use. The study also contextualizes the empirical model to Malaysia, among developing countries that have witnessed a rapid proliferation of digital growth but are vulnerable to idiosyncratic risk and volatility underlying the different stages of technological advancement. Two different results were found when examining the empirical model by the types of users. Interested users and the general public were more concerned about the reliability aspect of security, whereas non-interested users were more concerned about the multi-functional aspect of convenience. The empirical results showed that the dual strategy of 'ensuring convenience' and 'assuring security' could encourage mobile payment platform adoption in Malaysia. 
Therefore, businesses and platform service providers should take appropriate measures in designing the reliability and multi-functional aspects of a gamified mobile payment platform.

This study is not without limitations. One major limitation was that the survey targeted users who were assumed to have Internet or mobile data access with at least one-year self-reported experience using a gamified mobile payment platform. Based on the sample collected from an urban region of Malaysia, this study may not be generalized to other parts of the country. Moreover, as users gain experience and move to more advanced mobile payment platforms, the empirical results based on cross-sectional data may no longer apply at a later point in time. Future studies should consider including non-internet or non-mobile users in the sample using a probabilistic sampling method for better sample representation in Malaysia. A longitudinal study would also be useful to track changes in user perception over time.

\section{Acknowledgments}

Special thanks to collaborators at BlockChain Japan, BlockChain Investors, GlobalCLAS Technology, and Monash Global Asia in the 21st Century (GA21) multidisciplinary platform. Both authors contributed equally to this work.

\section{References}

Alhakami, A. S., \& Slovic, P. (1994). A Psychological Study of the Inverse Relationship Between Perceived Risk and Perceived Benefit. Risk Analysis, 14(6), 1085-1096. https://doi.org/10.1111/j.1539-6924.1994.tb00080.x

Alhassan, A., Li, L., Reddy, K., \& Duppati, G. (2020). Consumer acceptance and continuance of mobile money: Secondary data insights from Africa using the technology acceptance model. Australasian Journal of Information Systems, 24. https://doi.org/10.3127/AJIS.V24I0.2579

Alsawaier, R. (2018). The effect of gamification on motivation and engagement. International Journal of Information and Learning Technology, 35(1), 56-79. Retrieved from https://doi.org/10.1108/IJILT-02-2017-0009

Auer, R., Cornelli, G., \& Frost, J. (2020). Covid-19, cash, and the future of payment. Retrieved from https://www.bis.org/publ/bisbull03.pdf

Bank Negara Malaysia. (2019). Electronic Know-Your-Customer (e-KYC): Exposure Draft. In Know Your Customer. Retrieved from https://knowyourcustomer.com/bank-negaramalaysia-issues-e-kyc-policy/

Bank Negara Malaysia. (2020). Payment Statistics. Retrieved from https://www.bnm.gov.my/index.php?ch=ps\&pg=ps_stats\&lang=en.

Berry, L. L., Seiders, K., \& Grewal, D. (2002). Understanding service convenience. Journal of Marketing, 66(3), 1-17. https://doi.org/10.1509/jmkg.66.3.1.18505

Boksberger, P. E., \& Melsen, L. (2011, May). Perceived value: A critical examination of definitions, concepts and measures for the service industry. Journal of Services Marketing, Vol. 25, pp. 229-240. https://doi.org/10.1108/08876041111129209

Boost. (2019). Boost Introduces New Features for a More Rewarding Cashless Experience. Retrieved from https://www.myboost.com.my/news/boost-introduces-new-featuresfor-a-more-rewarding-cashless-experience/ 
Burmeister, O. K. (2015). Improving professional IT doctorate completion rates. Australasian Journal of Information Systems, 19, 55-70. https://doi.org/10.3127/ajis.v19i0.1073

Cao, C., \& Zhu, X. (2019). Strong anonymous mobile payment against curious third-party provider. Electronic Commerce Research, 19(3), 501-520. https://doi.org/10.1007/s10660018-9302-2

Capgemini. (2019). World Payments Report 2019. Retrieved from https:/www.capgemini.com/news/world-payments-report-2019/

Casino, F., Dasaklis, T. K., \& Patsakis, C. (2019, March 1). A systematic literature review of blockchain-based applications: Current status, classification and open issues. Telematics and Informatics, Vol. 36, pp. 55-81. https://doi.org/10.1016/j.tele.2018.11.006

Chang, Y.-W., \& Polonsky, M. J. (2012). The influence of multiple types of service convenience on behavioral intentions: The mediating role of consumer satisfaction in a Taiwanese leisure setting. International Journal of Hospitality Management, 31, 107-118. https://doi.org/10.1016/j.ijhm.2011.05.003

Chaudhry, S. A., Farash, M. S., Naqvi, H., \& Sher, M. (2016). A secure and efficient authenticated encryption for electronic payment systems using elliptic curve cryptography. Electronic Commerce Research, 16(1), 113-139. https://doi.org/10.1007/s10660-015-9192-5

Chauhan, S., Mukhopadhyay, S., \& Jaiswal, M. (2018). The adoption of mobile app for B2C transaction in platform marketplace: An empirical examination of key drivers. Journal of Information Technology Case and Application Research, 20(1), 9-22. https://doi.org/10.1080/15228053.2018.1453338

Chen, J., Zhu, Z., \& Xie, H. Y. (2004). Measuring intellectual capital: a new model and empirical study. Journal of Intellectual Capital, 5(1), 195-212. https://doi.org/10.1108/ 14691930410513003

Chen, X., \& Li, S. (2017). Understanding continuance intention of mobile payment services: An empirical study. Journal of Computer Information Systems, 57(4), 287-298. https://doi.org/10.1080/08874417.2016.1180649

Chew, J. (2019). Which E-wallet App Do Malaysians Use Frequently? Retrieved April 13, 2020, from iPrice Malaysia website: https://iprice.my/trends/insights/best-ewallet-malaysia/

Chutikulrungsee, T. T. (2016). Post Publication Review on Security and Privacy Concerns for Australian SMEs Cloud Adoption: Empirical Study of Metropolitan vs Regional SMEs. Australasian Journal of Information Systems, 20. https://doi.org/10.3127/ajis.v20i0.1369

Colby, C., \& Parasuraman, A. P. (2003). Technology still matters. Marketing Management, 12(4), 28-33. Retrieved from https://www.researchgate.net/publication/ 279697463_Technology_still_matters

Colwell, S. R., Aung, M., Kanetkar, V., \& Holden, A. L. (2008). Toward a measure of service convenience: multiple-item scale development and empirical test. Journal of Services Marketing, 22(2), 160-169. https://doi.org/10.1108/08876040810862895

Copeland, M. (1923). Relation of Consumers' Buying Habits to Marketing Methods. Harvard Business Review1, 1(April), 282-289 
Davis, F. D. (1989). Perceived usefulness, perceived ease of use, and user acceptance of information technology. MIS Quarterly, 13(3), 319-339. https://doi.org/10.2307/249008

Davis, Fred D., Bagozzi, R. P., \& Warshaw, P. R. (1989). User Acceptance of Computer Technology: A Comparison of Two Theoretical Models. Management Science, 35(8), 982-1003. https://doi.org/10.1287/mnsc.35.8.982

de Kerviler, G., Demoulin, N. T. M., \& Zidda, P. (2016). Adoption of in-store mobile payment: Are perceived risk and convenience the only drivers? Journal of Retailing and Consumer Services, 31, 334-344. https://doi.org/10.1016/j.jretconser.2016.04.011

Economic Planning Unit. (2015). Eleventh Malaysia Plan, 2016-2020. Retrieved from https://www.mea.gov.my/en/rmk/eleventh-malaysia-plan-2016-2020

Farquhar, J. D., \& Rowley, J. (2009). Convenience: a services perspective. Marketing Theory, 9(4), 425-438. https://doi.org/10.1177/1470593109346894

Fong, V. (2020, June 8). Malaysia to Spend RM 1.2 Billion Promoting E-Wallets in 2020. FinTech Malaysia. Retrieved from https://fintechnews.my/23971/e-wallets-malaysia/e-walletmalaysia-pejana/

Gensler, S., Verhoef, P. C., \& Böhm, M. (2012). Understanding consumers' multichannel choices across the different stages of the buying process. Marketing Letters, 23(4), 9871003. https://doi.org/10.1007/s11002-012-9199-9

Gupta, M. P., \& Dubey, A. (2016). E-Commerce- Study of Privacy, Trust and Security from Consumer' s Perspective. Computer Science and Mobile Computing

Hair, J.F., Hult, G. T. M., Ringle, C. M., \& Sarstedt, M. (2014). A Primer on Partial Least Squares Structural Equation Modeling (PLS-SEM). Thousand Oaks, CA: Sage Publication

Hair, J. F., Risher, J. J., Sarstedt, M., \& Ringle, C. M. (2019). When to use and how to report the results of PLS-SEM. European Business Review, 30(1), 2-24. https://doi.org/10.1108/EBR11-2018-0203

Hair, J. F., Sarstedt, M., Ringle, C. M., \& Gudergan, S. P. (2018). Advanced Issues in Partial Least Squares Structural Equation Modeling (PLS-SEM). Thousand Oaks, CA: Sage Publication

Harrison, D. E., Hair, J. F., \& Ajjan, H. (2021). Essentials of Marketing Analytics (1st ed.). McGraw-Hill Education

Harrison, R., Scheela, W., Lai, P. C., \& Vivekarajah, S. (2018). Beyond institutional voids and the middle-income trap: The emerging business angel market in Malaysia. Asia Pacific Journal of Management, 35(4), 965-991. https://doi.org/10.1007/s10490-017-9535-y

Henseler, J., Dijkstra, T. K., Sarstedt, M., Ringle, C. M., Diamantopoulos, A., Straub, D. W., ... Calantone, R. J. (2014). Common Beliefs and Reality about Partial Least Squares: Comments on Rönkkö \& Evermann (2013). Organizational Research Methods, 17(2), 182-209. https://doi.org/https://doi.org/10.1177/1094428114526928

Henseler, J., Ringle, C. M., \& Sarstedt, M. (2015). A new criterion for assessing discriminant validity in variance-based structural equation modeling. Journal of Academic of Marketing Science, 43(1), 115-135. https://doi.org/10.1007/s11747-014-0403-8 
Henseler, J., Ringle, C. M., \& Sarstedt, M. (2015). Testing measurement invariance of composites using partial least squares. International Marketing Review, 33(3), 405-431. https://doi.org/10.1108/IMR-09-2014-0304

Hofacker, C. F., de Ruyter, K., Lurie, N. H., Manchanda, P., \& Donaldson, J. (2016). Gamification and Mobile Marketing Effectiveness. Journal of Interactive Marketing, 34, 25-36. https://doi.org/10.1016/j.intmar.2016.03.001

Högberg, J., Shams, P., \& Wästlund, E. (2019). Gamified in-store mobile marketing: The mixed effect of gamified point-of-purchase advertising. Journal of Retailing and Consumer Services, 50, 298-304. https://doi.org/10.1016/j.jretconser.2018.07.004

Hollebeek, L. D., Das, K., \& Shukla, Y. (2021). Game on! How gamified loyalty programs boost customer engagement value. International Journal of Information Management, 102308. https://doi.org/10.1016/j.ijinfomgt.2021.102308

Huang, R. (2020, March 9). WHO Encourages Use of Contactless Payments Due to COVID-19. Forbes. Retrieved from https://www.forbes.com/sites/rogerhuang/2020/03/09/whoencourages-use-of-digital-payments-due-to-covid-19/?sh=59ac5feb41eb

Huotari, K., \& Hamari, J. (2017). A definition for gamification: anchoring gamification in the service marketing literature. Electronic Markets, 27(1), 21-31. https://doi.org/10.1007/s12525-015-0212-z

Jiang, L. (Alice), Yang, Z., \& Jun, M. (2013). Measuring consumer perceptions of online shopping convenience. Journal of Service Management, 24(2), 191-214. https://doi.org/10.1108/09564231311323962

Johnson, V. L., Kiser, A., Washington, R., \& Torres, R. (2018). Limitations to the rapid adoption of M-payment services: Understanding the impact of privacy risk on M-Payment services. Computers in Human Behavior. https://doi.org/10.1016/j.chb.2017.10.035

Kaufmann, H. R. (2014). Handbook of research on managing and influencing consumer behavior. In Handbook of Research on Managing and Influencing Consumer Behavior. https://doi.org/10.4018/978-1-4666-6547-7

Kim, C., Mirusmonov, M., \& Lee, I. (2010). An empirical examination of factors influencing the intention to use mobile payment. Computers in Human Behavior, 26(3), 310-322. https://doi.org/10.1016/j.chb.2009.10.013

Kim, H. W., Chan, H. C., \& Gupta, S. (2007). Value-based Adoption of Mobile Internet: An empirical investigation. Decision Support Systems, 43(1), 111-126. https://doi.org/10.1016/j.dss.2005.05.009

Kumar, R., Sachan, A., \& Kumar, R. (2020). Impact of service delivery system process and moderating effect of perceived value in internet banking adoption. Australasian Journal of Information Systems, 24. https://doi.org/10.3127/ajis.v24i0.1923

Lai, P. C. (2017). Security as an Extension to TAM Model: Consumers' Intention to Use a Single Platform E-Payment. Asia-Pacific Journal of Management Research and Innovation, 13(3-4), 110-119. https://doi.org/10.1177/2319510x18776405

Lai, P. C., \& Scheela, W. (2018). Convergence of Technology in the E-Commerce World and Venture Capital Landscape in South East Asia. In Global Entrepreneurship and New 
Venture Creation in the Sharing Economy (pp. 149-268). Retrieved from https://www.igi-global.com/chapter/convergence-of-technology-in-the-e-commerceworld-and-venture-capital-landscape-in-south-east-asia/186365

Lai, P. C., Toh, E. B. H., \& Alkhrabsheh, A. A. (2019). Empirical Study of Single Platform EPayment in South East Asia. In R. C. Ho (Ed.), Strategies and Tools for Managing Connected Consumers (pp. 252-278). https://doi.org/10.4018/978-1-5225-9697-4.ch015

Lee, Z. W., \& Khaw, D. P. T. (2018). Transforming Mobile Phones into E-Wallets in Malaysia. Retrieved from https://www.bnm.gov.my/files/publication/qb/2018/Q2/p7.pdf.

Lemon, K. N., \& Verhoef, P. C. (2016). Understanding customer experience throughout the customer journey. Journal of Marketing, 80(6), 69-96. https://doi.org/10.1509/jm.15.0420

Liew, E. J. Y., Vaithilingam, S., \& Nair, M. (2014). Facebook and Socio-economic Benefits in the Developing World. Behaviour \& Information Technology, 33(4), 345-360. https://doi.org/10.1080/0144929X.2013.810775

Lim, W. M. (2018). Dialectic antidotes to critics of the technology acceptance model: Conceptual, methodological, and replication treatments for behavioural modelling in technology-mediated environments. Australasian Journal of Information Systems, 22. https://doi.org/10.3127/ajis.v22i0.1651

Linger, H., \& Hasan, H. (2020). Making IS Relevant in a Connected World. Australasian Journal of Information Systems, 24. https://doi.org/10.3127/ajis.v24i0.2509

Liu, Z., Ben, S., \& Zhang, R. (2019). Factors affecting consumers' mobile payment behavior: a meta-analysis. Electronic Commerce Research, 19(3), 575-601. https://doi.org/10.1007/s10660-019-09349-4

Miao, M., \& Jayakar, K. (2016). Mobile payments in Japan, South Korea and China: Crossborder convergence or divergence of business models? Telecommunications Policy, 40(2-3), 182-196. https://doi.org/10.1016/j.telpol.2015.11.011

Morosan, C., \& DeFranco, A. (2016). It's about time: Revisiting UTAUT2 to examine consumers' intentions to use NFC mobile payments in hotels. International Journal of Hospitality Management, 53, 17-29. https://doi.org/10.1016/j.ijhm.2015.11.003

Mukerji, M., \& Roy, P. S. (2019). Platform Interactions and Emergence of an Organizational Field: Case Study on Ola. Australasian Journal of Information Systems, 23. https://doi.org/10.3127/ajis.v23i0.2113

Nakamoto, S. (2008). Bitcoin: A Peer-to-Peer Electronic Cash System. Retrieved November 20, 2020, from https://www.klausnordby.com/bitcoin/Bitcoin_Whitepaper_Document_ HD.pdf.

Nayal, P., Pandey, N., \& Paul, J. (2021). Examining m-coupon redemption intention among consumers: A moderated moderated-mediation and conditional model. International Journal of Information Management, 57, 102288-. https://doi.org/10.1016/ j.ijinfomgt.2020.102288

O'Reilly, P., Duane, A., \& Andreev, P. (2012). To M-Pay or not to M-Pay-realising the potential of smart phones: Conceptual modeling and empirical validation. Electronic Markets, 22(4), 229-241. https://doi.org/10.1007/s12525-012-0105-3 
Panhwer, P., Pitafi, A., Memon, M. S., \& Memon, A. (2020). Awareness and Reason towards Slow Adoption of E-Payment System: Study of Hyderabad. Annals of Contemporary Developments in Management \& HR, 2(1), 6-21. https://doi.org/10.33166/acdmhr.2020.01.002

Parizi, R. M., \& Dehghantanha, A. (2018). On the understanding of gamification in blockchain systems. Proceedings - 2018 IEEE 6th International Conference on Future Internet of Things and Cloud Workshops, W-FiCloud 2018, 214-219. https://doi.org/10.1109/WFiCloud.2018.00041

Poushter, J., Bishop, C., \& Chew, H. (2018). Social Media Use Continues to Rise in Developing Countries but Plateaus Across Developed Ones. Retrieved from https://www.pewresearch.org/global/2018/06/19/social-media-use-continues-to-rise-indeveloping-countries-but-plateaus-across-developed-ones/.

Putri, M. F., Hidayanto, A. N., Negara, E. S., Budi, N. F. A., Utari, P., \& Abidin, Z. (2019). Gratification Sought in Gamification on Mobile Payment. ICICOS 2019 - 3rd International Conference on Informatics and Computational Sciences: Accelerating Informatics and Computational Research for Smarter Society in The Era of Industry 4.0, Proceedings. https://doi.org/10.1109/ICICoS48119.2019.8982424

PWC. (2019). It's time for a consumer-centred metric: Introducing "return on experience": Global consumer insights survey. Retrieved from https://www.pwc.com/gx/en/ consumer-markets/consumer-insights-survey/2019/ report.pdf

Ramadan, Z. B., \& Farah, M. F. (2017). The Pokémonisation of the first moment of truth. International Journal of Web Based Communities, 13(2), 262-277. https://doi.org/10.1504/IJWBC.2017.084417

Ringle, C. M., \& Sarstedt, M. (2016). Gain more insight from your PLS-SEM results the importance-performance map analysis. Industrial Management and Data Systems, Vol. 116, pp. 1865-1886. https://doi.org/10.1108/IMDS-10-2015-0449

Ringle, C. M., Wende, S., \& Becker, J.-M. (2015, January 5). SmartPLS 3. Retrieved from http://www.smartpls.com

Sánchez-Fernández, R., \& Iniesta-Bonillo, M. Á. (2007). The concept of perceived value: A systematic review of the research. Marketing Theory, 7(4), 427-451. https://doi.org/10.1177/1470593107083165

Schmida, S., Bernard, J., Zakaras, T., Lovegrove, C., \& Swingle, C. (2017). Connecting the Next Four Billion: Strengthening the Global Response for Universal Internet Access. Retrieved February 12, 2020, from USAID, Dial Digital Impact Alliance and SSG Advisors website: www.usaid.gov/sites/default/files/documents/15396/Connecting_the_Next_Four_Billio n-20170221_FINAL.pdf

Seiders, K., Voss, G. B., Godfrey, A. L., \& Grewal, D. (2007). SERVCON: Development and validation of a multidimensional service convenience scale. Journal of the Academy of Marketing Science, 35(1), 144-156. https://doi.org/10.1007/s11747-006-0001-5

Senarathna, I., Yeoh, W., Warren, M., \& Salzman, S. (2016). Security and privacy concerns for Australian SMEs cloud adoption: Empirical study of metropolitan vs regional SMEs. Australasian Journal of Information Systems. https://doi.org/10.3127/ajis.v20i0.1193 
Sharma, S. K., \& Gupta, J. N. D. (2009). Identifying Factors for Lack of E-commerce in Developing Countries. In K. Rouibah, O. Khalil, \& A. Hassanien (Eds.), Emerging Markets and E-Commerce in Developing Economies (pp. 70-88). Hershey, PA: Information Science Reference.

Shin, D. H. (2009). Towards an understanding of the consumer acceptance of mobile wallet. Computers in Human Behavior, 25(6), 1343-1354. https://doi.org/10.1016/ j.chb.2009.06.001

Shmueli, G., Sarstedt, M., Hair, J. F., Cheah, J. H., Ting, H., Vaithilingam, S., \& Ringle, C. M. (2019). Predictive model assessment in PLS-SEM: guidelines for using PLSpredict. European Journal of Marketing, 53(11), 2322-2347. https://doi.org/10.1108/EJM-02-20190189

Ström, R., Vendel, M., \& Bredican, J. (2014). Mobile marketing: A literature review on its value for consumers and retailers. Journal of Retailing and Consumer Services, 21(6), 10011012. https://doi.org/10.1016/j.jretconser.2013.12.003

Tashiro, M. (2018). Major Japanese corporation driving cryptocurrency usage» Brave New Coin. Retrieved February 24, 2020, from https://bravenewcoin.com/insights/majorjapanese-corporation-driving-cryptocurrency-usage

Taylor, S., \& Todd, P. (1995). Understanding information technology usage: A test of competing models. Information Systems Research, 6(2), 144-176.

Teo, A. C., Tan, G. W. H., Ooi, K. B., Hew, T. S., \& Yew, K. T. (2015). The effects of convenience and speed in m-payment. Industrial Management and Data Systems, 115(2), 311-331. https://doi.org/10.1108/IMDS-08-2014-0231

The Star. (2020, June 12). Boost supports government's e-wallet initiatives. Retrieved from https://www.thestar.com.my/business/business-news/2020/06/12/boost-supportsgovernments-e-wallet-initiatives

Truong, V. N. X., Nkhoma, M., \& Pansuwong, W. (2019). An Integrated Effectiveness Framework of Mobile In-App Advertising. Australasian Journal of Information Systems, 23. https://doi.org/10.3127/ajis.v23i0.1971

Venkatesh, V., \& Davis, F. D. (2000). A theoretical extension of the technology acceptance model: four longitudinal field studies. Management Science, 6, 144-176.

Venkatesh, V., Morris, M. G., Gordon, B. D., \& Davis, F. D. (2003). User Acceptance of Information Technology: Toward a Unified View. MIS Quarterly, 27(3), 425-478. Retrieved from http://www.jstor.org/stable/30036540

Vishwakarma, P., Mukherjee, S., \& Datta, B. (2020). Travelers' intention to adopt virtual reality: A consumer value perspective. Journal of Destination Marketing and Management, 17. https://doi.org/10.1016/j.jdmm.2020.100456

Weir, C. S., Douglas, G., Carruthers, M., \& Jack, M. (2009). User perceptions of security, convenience and usability for ebanking authentication tokens. Computers and Security, 28(1-2), 47-62. https://doi.org/10.1016/j.cose.2008.09.008 
Weissman, A. (2012). Convenience: The third essential of a customer-centric business. Retrieved February 24, 2020, from UX Magazine website: https://uxmag.com/articles/convenience

Wu, J., Liu, L., \& Huang, L. (2017). Consumer acceptance of mobile payment across time Antecedents and moderating role of diffusion stages. Industrial Management and Data Systems, 117(8), 1761-1776. https://doi.org/10.1108/IMDS-08-2016-0312

Xi, N., \& Hamari, J. (2020). Does gamification affect brand engagement and equity? A study in online brand communities. Journal of Business Research, 109, 449-460. https://doi.org/10.1016/j.jbusres.2019.11.058

Xin, H., Techatassanasoontorn, A. A., \& Tan, F. B. (2015, June 1). Antecedents of consumer trust in mobile payment adoption. Journal of Computer Information Systems, Vol. 55, pp. 1-10. https://doi.org/10.1080/08874417.2015.11645781

Xu, L., Chen, L., Gao, Z., Carranco, L., Fan, X., Shah, N., ... Shi, W. (2020). Supporting Blockchain-Based Cryptocurrency Mobile Payment with Smart Devices. IEEE Consumer Electronics Magazine, 9(2), 26-33. https://doi.org/10.1109/MCE.2019.2953734

Yang, Y., Asaad, Y., \& Dwivedi, Y. (2017). Examining the impact of gamification on intention of engagement and brand attitude in the marketing context. Computers in Human Behavior, 73, 459-469. https://doi.org/10.1016/j.chb.2017.03.066

Yuniarta, G. A., \& Purnamawati, G. A. (2021). Psychological dimensions and practical strategies: MSME and mobile payment adoption. Management Science Letters, 11, 577586. https://doi.org/10.5267/j.msl.2020.9.009

Zelezny-Green, R., Voslon, S., \& Conole, G. (2018). Digital inclusion for low-skilled and lowliterate people: a landscape review - UNESCO Digital Library. Retrieved from https://unesdoc.unesco.org/ark:/48223/pf0000261791

Zhang, J., Xu, N., \& Bai, S. (2020). The optimal pricing decisions for e-tailers with different payment schemes. Electronic Commerce Research, 1-28. https://doi.org/10.1007/s10660020-09396-2

Copyright: ( 2021 authors. This is an open-access article distributed under the terms of the Creative Commons Attribution-NonCommercial 3.0 Australia License, which permits noncommercial use, distribution, and reproduction in any medium, provided the original author and AJIS are credited.

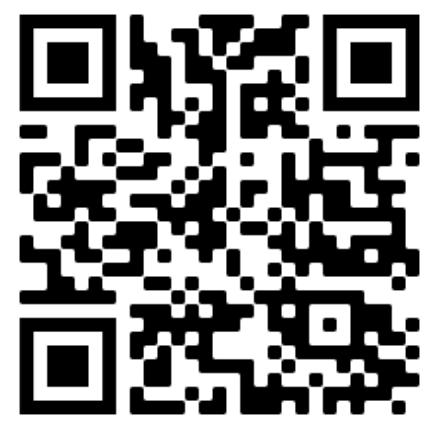

